\title{
Energy savings due to the use of shallow body temperature reduction in overwintering Northern Cardinals
}

\author{
Paul J. Schaeffer ${ }^{*}$, Maria C. Komer and Keely R. Corder
}

\begin{abstract}
Background: Northern Cardinals (Cardinalis cardinalis) are able to endure drastic seasonal variations in ambient temperature. Many endotherms in these conditions utilize heterothermy (e.g., torpor) to conserve energy by adjusting their body temperatures according to changing environmental conditions. Previous research shows that cardinals reduce energy expenditure during winter nights. By examining whole-animal function, we asked whether this reduced metabolism was a result of decreased activity or an induced state of torpor. We measured body mass, percent fat content, metabolic rate $\left(\dot{\mathrm{V}} \mathrm{O}_{2}\right)$ across a range of ambient temperatures and body temperature $\left(\mathrm{T}_{\mathrm{b}}\right)$ using data loggers during both summer (August to early September) and winter (December to January) conditions. We hypothesized that: (a) daily winter $\mathrm{T}_{\mathrm{b}}$ fluctuations would reveal an induced torpor, and (b) alterations of insulation would play a significant role in thermoregulation.

Results: Although insulation in the form of fat stores was higher in the winter, there was no seasonal difference in whole body conductance. We found no evidence for torpor, but found a slight depression in overall circadian temperature rhythms for the winter animals compared to summer animals, resulting in a predicted $10-16 \%$ savings in daily energy expenditure.

Conclusions: Our findings support recent work showing that thermoregulatory mechanisms are not as fixed as previously thought and, while fat deposits may function to increase insulation, they are more likely important for fuel storage. These data identify subtle changes in the homeostatic set point for body temperature and show that these slight alterations can have significant impacts on daily energy expenditure in wild birds.
\end{abstract}

Keywords: Heterothermy, Winter survival, Seasonality, Avian, Homeostasis

\section{Background}

Temperate overwintering birds regularly experience temperatures below their thermoneutral zone and require behavioral, morphological and physiological mechanisms to regulate body temperature. Maintaining normothermia in low ambient temperatures $\left(T_{\mathrm{a}}\right)$ involves considerable energy expenditure for thermoregulation. Heterothermy is an energy-saving strategy used by many endotherms, in which body temperatures $\left(T_{\mathrm{b}}\right)$ are adjusted in response to varying environmental conditions. The most common patterns of heterothermy

\footnotetext{
*Correspondence: schaefpj@miamioh.edu

Department of Biology, Miami University, 212 Pearson Hall, Oxford, $\mathrm{OH}$ 45056, USA
}

observed in diurnal overwintering birds are torpor, defined as a sustained decrease in metabolic rate and $T_{\mathrm{b}}$ below normothermia $[5,13]$, and more shallow reductions in $\mathrm{T}_{\mathrm{b}}$ to save energy and conserve seasonal fat stores during times of extreme low $T_{\mathrm{a}}$ and/or reduced food availability [22]. The use of nocturnal $T_{\mathrm{b}}$ reductions and torpor is well documented in birds, and generally entails daily shifts between an optimally high $T_{\mathrm{b}}$ during active daytime hours and low $T_{\mathrm{b}}$ at night $[22,24,25]$. For example, the Malachite Sunbird (Nectarinia famosa) displays rest-phase $T_{\mathrm{b}}$ reductions and torpor at ambient temperatures of $10{ }^{\circ} \mathrm{C}$ and lower, decreasing $T_{\mathrm{b}}$ by $15{ }^{\circ} \mathrm{C}$ [10]. In addition, the use of nocturnal $T_{\mathrm{b}}$ reductions resulted in energy savings of 7-50 \% in Mountain Chickadees 
(Poecile gambeli) and $10-28 \%$ in Juniper Titmice (Baeolophus ridgwayi; [7]). Species that utilize this strategy are spread across phylogeny, zoogeographic zones, and body mass ranges [22].

However, not all species utilize this strategy [22, 23] and some species capable of torpor only do so during times of starvation $[23,25]$, which suggests there is some cost associated with torpor. In addition to a reduced $T_{\mathrm{b}}$, torpor also involves a regimented reduction in activity level and metabolic rate, and can negatively impact an individual's response to external stimuli, flight ability upon arousal and reproductive success [3, 11, 15, 23, 25]. Considering the costs associated with heterothermy, it may be a benefit to adjust the depth and duration of $T_{b}$ reductions to avoid these costs while still maintaining the equivalent energy savings.

Patterns of avian heterothermy have generally been considered to follow a rest-phase reduced $T_{\mathrm{b}}$ and activephase optimal $T_{\mathrm{b}}$ framework. Contrary to this perspective, recent findings suggest that a more shallow reduction in $T_{\mathrm{b}}$ can be important in energy savings, as it may serve to balance the trade-off between the risk of starvation and the risks associated with deeper reductions of $T_{\mathrm{b}}$ and metabolic rate [20]. Recent studies provide evidence for a more flexible use of thermoregulation in birds occupying varying environmental conditions. For example, Lewden et al. [20] showed consistent use of daytime $T_{\mathrm{b}}$ reduction in free-living birds captured at low $T_{\mathrm{a}}$, independent of the size of an individual's energy reserves and metabolic performance. Smit et al. [33] showed that even small changes in ambient temperature can have significant effects on set-point $\mathrm{T}_{\mathrm{b}}$ and the use and magnitude of heterothermy within different populations of the same species. These results suggest the use and timing of heterothermy may be a variable individual choice, informed primarily by environmental cues.

In a recent study [31], we measured seasonal variation in field metabolic rate (FMR) of free-living Northern Cardinals (Cardinalis cardinalis; hereafter 'cardinals'), using heart rate telemetry. Cardinals range from southern Mexico to the Great Lakes in North America, and, as a non-migratory bird species, experience fairly robust seasonal $T_{\mathrm{a}}$ variations while overwintering in southwestern Ohio $\left(39^{\prime} 30^{\circ} \mathrm{N}\right)$. At this location, cardinals exhibit significantly higher metabolic rates during winter, presumably in response to the challenge of thermoregulation. Of particular interest, during winter nights, the FMR of cardinals is lower than during the day, although ambient temperatures are at daily minima [31]. While activity costs were very low during the night, thermoregulatory costs should have been high. Thus, this species provides a model for exploring the role of both day- and night-time
$T_{\mathrm{b}}$ reduction in a songbird living near the northern edge of its range.

By examining whole-animal function, we asked whether decreased metabolic activity during winter nights was a result of decreased activity or an induced state of torpor. We also considered whether insulation increases in winter to reduce energetic needs. We measured body mass, percent fat content, and metabolic rate $\left(\dot{V} \mathrm{O}_{2}\right)$ across a range of ambient temperatures and body temperature using data loggers during both summer (August to early September) and winter (December to January) conditions. As cardinals are able to endure drastic seasonal $T_{\mathrm{a}}$ variations, we hypothesized that to conserve energy: (a) winter nighttime $T_{\mathrm{b}}$ would be depressed compared to summer as cardinals exhibit an induced torpor, and (b) insulation would play a significant role in reducing the thermoregulatory demand.

In this study, although FMR was previously reported to be lowest during winter night, the coldest period monitored, we were able to verify that FMR was not dropping due to torpor. Instead, we found a slight depression in circadian $\mathrm{T}_{\mathrm{b}}$ rhythms for the winter animals compared to summer animals resulting in reduced body temperatures throughout the day. Although body fat content was significantly increased in the winter birds compared to summer, metabolic rate measurements did not differ across measurement temperatures between summer and winter animals. Our findings support the idea that thermoregulatory mechanisms are not as fixed as generally thought and while fat deposits may function to increase insulation, they are more likely important as fuel storage. These data identify subtle changes in seasonal thermoregulation, and suggest that mechanisms behind and ecological importance of these alterations in thermoregulatory states should be further assessed.

\section{Methods}

\section{Study species and field sites}

Cardinals were captured with mist nets at the Miami University Ecology Research Center $\left(39^{\circ} 30^{\prime} \mathrm{N}, 84^{\circ} 45^{\prime} \mathrm{W}\right)$, in Southwest Ohio from 16 January to 21 March, 2012 and 2014 (winter) and from 8 August to 4 September, 2012 and 2013 (summer). These times were chosen to ensure that birds were experiencing the challenge of winter cold or were captured following the summer breeding season. All birds were caught between sunrise and early afternoon and release was always at least $1 \mathrm{~h}$ before sunset to ensure a successful transition back to the environment or aviary following laboratory procedures described below. Thus, animals were kept in the animal facility for no more than several hours. Animals with implanted temperature loggers were kept for 2 weeks as described below. 
All birds were captured under Ohio Department of Natural Resources permit no. 11-152 and US Fish and Wildlife Service permit no. MB158451-1. All animal experimentation was approved by the Institutional Animal Care and Use Committee of Miami University (protocol no. 736) and complied with the regulations of the National Institutes of Health as well as the laws of the United States.

\section{Body composition analysis}

We measured total body mass, fat mass and lean mass to determine whether body size and/or composition changed across seasons. Upon capture, cardinals (summer, $n=19$; winter, $n=19$ ) were weighed using a digital scale with resolution to $0.01 \mathrm{~g}$ (Scout Pro, Pine Brook, NJ, USA). We then determined fat mass and lean mass using MRI-based body composition analysis (EchoMRI-SuperFLEX $^{\mathrm{TM}}$, EchoMRI, Houston TX, USA). The instrument was calibrated using the manufacturer-provided calibration vessel. These measurements do not detect feather weight, but do include gut contents. Following these measures, we either measured metabolic rates of birds using respirometry or surgically implanted a temperature logger, as described below.

\section{Respirometry}

As neither feather mass nor the contribution of feathers to insulation is quantified by NMR-based body composition analysis, we determined body conductance, a functional measure of heat loss, using open flow respirometry. We used indirect calorimetry to determine oxygen consumption rates $\left(\dot{V} \mathrm{O}_{2}\right)$ at ambient temperatures ranging from $\sim 5$ to $32{ }^{\circ} \mathrm{C}$. These data were used to determine conductance of both winter (14-23 February; $n=13)$ and summer ( 8 August to 4 September; $n=13$ )-acclimatized birds following Scholander et al. [30]. In all cases, positive pressure gas flow (room air) was regulated by a mass flow meter $(0-5 \mathrm{~L} / \mathrm{min}$, Sierra Instruments, Monterey, CA, USA) controlled by a flow controller (model MFC-2; Sable Systems, Las Vegas NV, USA) at $1.4 \mathrm{~L} / \mathrm{min}$. Air then flowed into a 2.5-liter water-jacketed Plexiglass chamber containing the animal before passing through a $\mathrm{CO}_{2}$ analyzer (FoxBox Portable Oxygen Analysis System, Sable Systems, Las Vegas NV, USA), a drierite column and an $\mathrm{O}_{2}$ analyzer (FoxBox System). Carbon dioxide was not removed from the gas at any point. Voltage outputs from the flow controller and gas analyzers were collected at a rate of one sample per second using the Expedata program (Sable Systems).

Prior to each measurement, the chamber was brought to a target temperature by passing water through the outer jacket and a temperature-controlled circulating water bath (model F12, Julabo USA, Allentown PA,
USA). During measurements, the bird was enclosed in the metabolic chamber, $\mathrm{T}_{\mathrm{a}}$ was monitored with a copper/ constantan thermocouple thermometer suspended in the center of the chamber, above the animal (HH806AU, Omega Inc., Stamford CT, USA) and the apparatus was covered with a dark box to keep the bird calm. Activity was monitored by listening for movement in the chamber. The bird remained in the chamber for 45-60 min to achieve a steady-state metabolic rate. All respirometry experiments were conducted between late morning and at least $2 \mathrm{~h}$ before sunset.

Data for analysis were selected from a 5-min period while the bird was at rest and the gases were at a steady state. $\dot{V} \mathrm{O}_{2}$ was calculated using the equation from the Expedata manual (Sable Systems):

$$
\begin{aligned}
\dot{V} \mathrm{O}_{2}= & \mathrm{STP} \cdot \mathrm{FR} \cdot\left(\left(\mathrm{F}_{\mathrm{i}} \mathrm{O}_{2}-\mathrm{F}_{\mathrm{e}} \mathrm{O}_{2}\right)-\mathrm{F}_{\mathrm{e}} \mathrm{O}_{2}\right. \\
& \left.\times\left(\mathrm{F}_{\mathrm{e}} \mathrm{CO}_{2}-\mathrm{F}_{\mathrm{i}} \mathrm{CO}_{2}\right)\right) /\left(1-\mathrm{F}_{\mathrm{e}} \mathrm{O}_{2}\right),
\end{aligned}
$$

where STP is standard temperature and pressure corrections, FR flow rate, $\mathrm{F}_{\mathrm{i}} \mathrm{O}_{2}$ and $\mathrm{F}_{\mathrm{e}} \mathrm{O}_{2}$ fractional content of oxygen in incurrent and excurrent air, respectively, and $\mathrm{F}_{\mathrm{i}} \mathrm{CO}_{2}$ and $\mathrm{F}_{\mathrm{e}} \mathrm{CO}_{2}$ fractional content of carbon dioxide in incurrent and excurrent air, respectively.

\section{Temperature logging}

To determine continuous body temperature, after measurement of body composition, birds were anesthetized with inhaled isoflurane (5\% during induction and $1 \%$ for maintenance in oxygen at $1 \mathrm{~L} / \mathrm{min}$ ) and a $1-\mathrm{cm}$ incision was made across the abdomen. A Thermochron iButton (model DS1922L; iButtonLink, LLC, Whitewater WI, USA) was implanted into the abdominal cavity and the incision closed with nylon suture and cyanoacrylate glue. The iButton was programed to record body temperature once every $5 \mathrm{~min}$ at a resolution of $\pm 0.0625{ }^{\circ} \mathrm{C}$, with an approximately $36-\mathrm{h}$ delay before the first recording was made. After surgery, birds were transported to the Miami University Ecology Research Center $(\sim 30 \mathrm{~min})$ and released into an outdoor aviary. Birds were given commercial birdseed and water ad libitum. After 1-2 weeks, the animals were recaptured, euthanized and the data logger was recovered. Only complete days were analyzed. We collected a total of 24 days of $\mathrm{T}_{\mathrm{b}}$ data from a total of 4 individual cardinals in summer (24 August to 3 September) and a total of 69 days from 6 cardinals in winter (16 January to 6 March).

\section{Statistics}

For body, fat and lean mass, we compared summer and winter animals using a Student's $t$ test in JMP (version 11). To determine the lower critical temperature for each season, we initially performed a piecewise regression from the respirometry data using PROC NLIN in SAS 
(ver 9.3; SAS Institute, Cary NC USA). To compare the conductance across season, we then built a model including temperature and season effects in which the individual season inflection points (lower critical temperature) were translated to the same zero point and used as a fixed constant in a subsequent ANCOVA performed within the context of a segmented regression model with both seasons [1] using SAS (ver 9.3). To compare seasonality of body temperature, we compared a model with season, time of day and their interactions as fixed effects and animal and day as random effects to an identical model lacking season and the season by time interaction. A Chisquared test was then used to determine if season led to a significant difference in the models. We also report the Akaike information criterion (AIC) values and the Bayesian information criterion (BIC) values as further measures of model fit. Analysis was performed using R (v3.1.1; [26]). The level of significance was set at $p<0.05$ in all cases. All data are reported as mean \pm standard error except the lower critical temperatures which are mean (95\% confidence interval). The number of observations is listed in the corresponding methods above.

\section{Results and discussion}

We initially measured total body mass, fat mass and lean mass to determine whether body size and/or composition changed across seasons. Body mass was significantly higher in winter cardinals (Table $1 ; p<0.05$ ). One function of adiposity may serve as insulation, reducing the challenge of winter cold exposure, and we found that winter-caught cardinals had significantly higher fat mass (Table $1 ; p<0.05$ ). As lean mass did not differ between summer and winter (Table $1 ; p>0.05$ ), the increase in body mass was driven more by fat mass. Increased adiposity is a commonly observed characteristic of birds while overwintering at high latitudes $[8,18,31,34]$. As the majority of the adipose tissue appears to be subcutaneous, it may act as an insulation layer. However, it may be more important as a strategy for ensuring that energy stores are available during periods when weather does not permit sufficient foraging behavior $[6,8]$ or food resources are scarcer.

Table 1 Total body and fat mass are higher in winter compared to summer birds

\begin{tabular}{lcc}
\hline & Summer [19] & Winter [19] \\
\hline Body mass (g) & $40.78 \pm 0.78$ & $42.95 \pm 0.72^{*}$ \\
Lean mass (g) & $33.31 \pm 0.52$ & $32.39 \pm 0.41$ \\
Fat mass (g) & $0.84 \pm 0.12$ & $2.49 \pm 0.32^{*}$ \\
\hline
\end{tabular}

Data are presented as mean \pm SEM. with number of observations noted after each season

${ }^{*}$ A significant difference between groups
As neither feather mass nor the contribution of feathers to insulation is quantified by NMR-based body composition analysis, we determined body conductance, a functional measure of heat loss, using open flow respirometry. We measured metabolic rate of both winter and summer cardinals at a range of temperatures spanning the thermoneutral zone and well below (Fig. 1). The slope of the regression of metabolic rate against ambient temperatures below thermoneutral is the whole-animal conductance [30] and reveals the rate at which heat is lost (and thus must be produced to maintain $T_{\mathrm{b}}$ ) as a function of the change in $T_{a}$. There was no difference in conductance as regression analysis showed no significant effect of season $(t$ value $=1.68 ; p=0.11)$. Further, there was no significant effect of season on the lower critical temperature although summer at $28.0^{\circ} \mathrm{C}(25.1-30.9)$ appears higher than winter at $21.3^{\circ} \mathrm{C}(8.9-33.7)$. These data indicate that overwintering cardinals do not appear to reduce energy costs of thermoregulation by increasing insulation. It is worth noting that, if significant, the observed mean lower critical temperatures would be sufficiently divergent to lead to important energetic savings at intermediate temperatures, potentially a low sample size concern. These results are consistent with those of Cooper and Swanson [6], who report no seasonal difference in conductance in Black-capped Chickadees in South Dakota. However, winter-acclimatized Dark-eyed Juncos in Oregon and Australian Silvereyes decrease thermal conductance below thermoneutrality, indicating a greater contribution of insulation to winter acclimatization [21, 34]. Differences in the role of insulation may be explained by differences in species-specific response to cold or by varying geographic requirements for thermoregulation

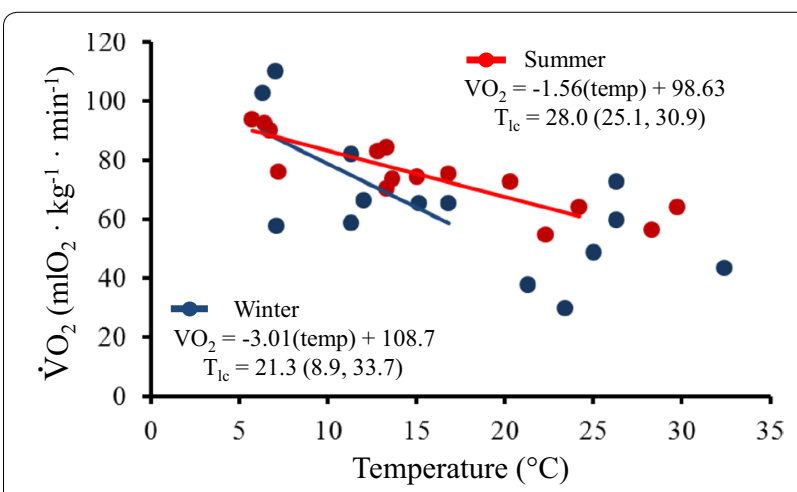

Fig. 1 Linear relationship between metabolic rate and ambient temperature $\left(T_{a}\right)$ in summer- and winter-acclimatized Northern Cardinals. Regression equations are shown, where the slope represents whole-animal conductance. There was no difference in conductance as regression analysis showed no significant effect of season. Lower critical temperatures as determined by piecewise regression are noted with $95 \% \mathrm{Cl}$ in parentheses 
relating to winter intensity, as harsher winter conditions (e.g., South Dakota) provide a stronger stimulus, but not necessarily the strongest response.

Another potential avenue for reducing energy expenditure during cold exposure is depression of body temperature. Data from wintering cardinals had revealed that field metabolic rate was lowest during the night, when ambient temperatures were at their lowest, suggesting metabolic rate depression via torpor [31]. Loggers recorded body temperature every 5 min (data archive: [27]). Mean data for each time point and every animal day revealed first, that overwintering cardinals do not undergo torpor. The nighttime body temperatures of both winter and summer cardinals were maintained at relatively high levels (Fig. 2). However, circadian patterns in body temperature did significantly differ between seasons. The model comparing effects of time, individual and season had the best fit with season included compared with those without season or season by time interactions, with lower AIC values (14163 vs. 13565), BIC values (14200 vs. 13616) and a highly significant Chi-squared test $\left(X^{2}\right.$ with $\left.2 d f=602 ; p<0.001\right)$. The difference in $\mathrm{T}_{\mathrm{b}}$ was most pronounced during the night. Winter nighttime body temperatures averaged $38.51{ }^{\circ} \mathrm{C}$, about $1.3{ }^{\circ} \mathrm{C}$ lower than the summer nighttime $T_{\mathrm{b}}$ of $39.87^{\circ} \mathrm{C}$ (Fig. 2).
Daytime temperatures were lower in winter as well, however, average winter body temperatures of $41.78{ }^{\circ} \mathrm{C}$ were not quite $1{ }^{\circ} \mathrm{C}$ lower than summer body temperatures of $42.64{ }^{\circ} \mathrm{C}$ (Fig. 2).

To determine the physiological relevance of this seasonal body temperature depression, we calculated the energy savings assuming that a $1{ }^{\circ} \mathrm{C}$ drop in body temperature is equal to an equivalent rise in ambient temperature. Using the regression equations derived from the respirometry experiments and our measures of body temperature, we calculated the change in metabolic rates across the range of temperatures measured. This yielded a predicted reduction of MR from 2.9 to $5.7 \%$ during the winter day and a predicted reduction of 4.5-9.0\% during the winter night (Table 2). We also calculated the expected reduction in metabolic rate based on a $Q_{10}$ effect. $Q_{10}$, the change in a rate process due to a 10 degree change in body temperature, is between 2 and 3 for metabolic rate, i.e., a two- to threefold increase in the rate is expected with a 10 degree increase in body temperature [29]. As $Q_{10}$ calculations only clearly apply for ectotherms or endotherms in torpor or hibernation, these calculations may be erroneous; however, given that we know little about the mild body temperature depression, we include these calculations for potential comparison.

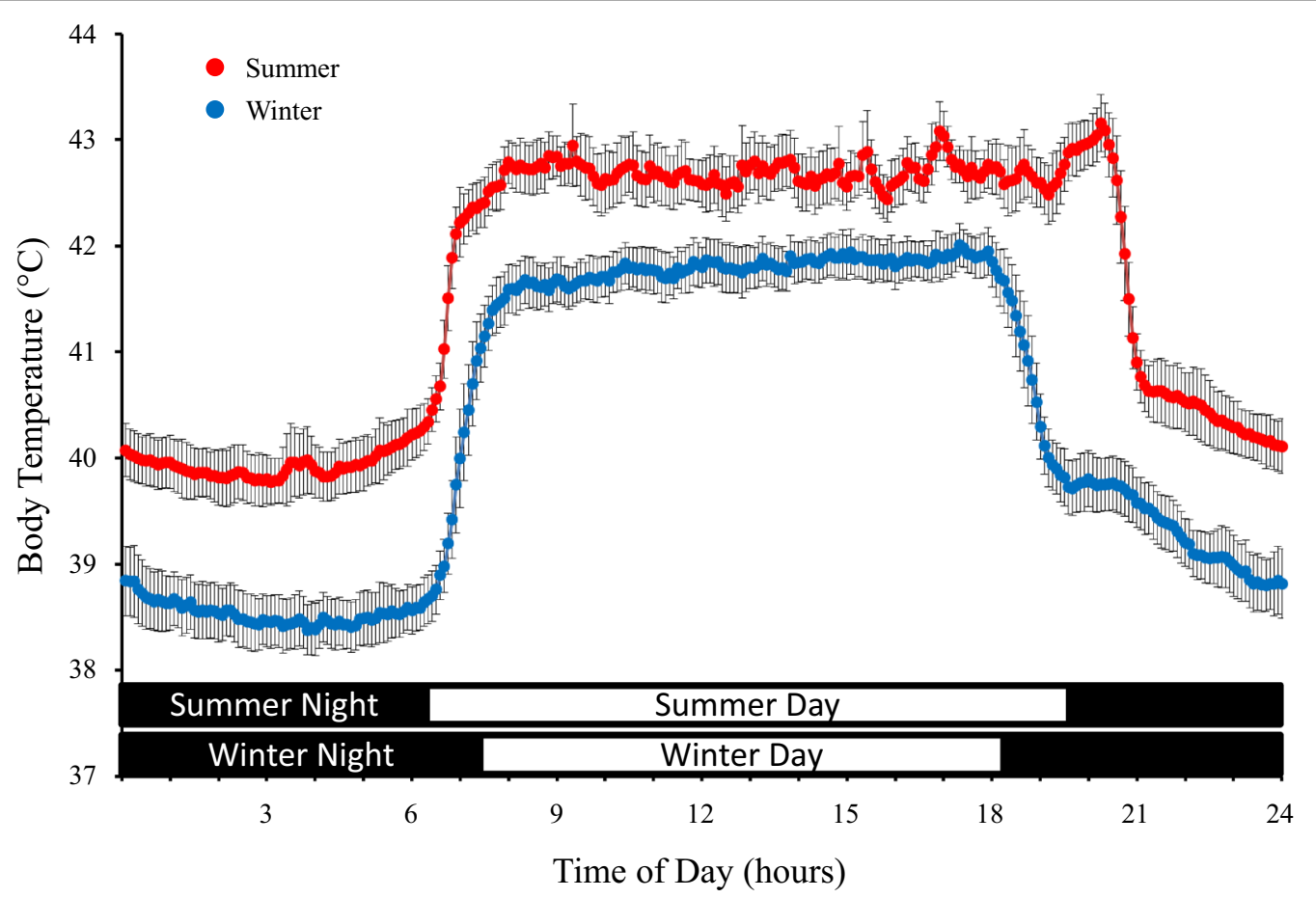

Fig. 2 Average body temperatures across the day of cardinals in semi-natural aviaries during summer and winter. iButton loggers implanted into the abdominal cavity recorded body temperature every $5 \mathrm{~min}$. Overwintering cardinals do not undergo torpor; however, nighttime body temperatures were about $1.3{ }^{\circ} \mathrm{C}$ lower in winter-acclimatized cardinals. Daytime body temperatures were not quite $1{ }^{\circ} \mathrm{C}$ lower in winter-acclimatized cardinals. Both nighttime and daytime body temperatures were highly significantly influenced by season. Data are presented as mean \pm SEM 
Table 2 Predicted change in field metabolic rates (FMR) calculated conductance values from Fig. 1 and assuming that the decrease in winter body temperature is equivalent to an equal increase in ambient temperature

\begin{tabular}{lll}
\hline Predicted \% increase in FMR & Winter night & Winter day \\
with summer $T_{b}$ & $2.9-5.7 \%$ & $4.5-9.0 \%$
\end{tabular}

The range in predicted energy savings represents the percent change across the measured $T_{\mathrm{a}}$. Note that although the predicted increment is constant at all temperatures, as FMR increases with decreasing $T_{\mathrm{a}}$, the percent savings will be lower at lower $T_{\mathrm{a}}$

Using this approach, we calculated predicted winter FMR using previously published values measured from the same population during similar time periods [31] and our measures of body temperature assuming $Q_{10}$ values of both 2 and 3 as any exact value is unknown for this species. It is worth noting that metabolic depression likely precedes the drop in $\mathrm{T}_{\mathrm{a}}$ [17], however, as temperature and metabolic rate remain closely correlated, the primary cause of reduced metabolism will not affect the conclusions of these calculations. Predicted values were compared with published measurements of FMR to determine the extent of energetic savings that could be attributed to observed $\mathrm{T}_{\mathrm{b}}$ depression (Table 3 ). Although body temperatures were only reduced by about one degree, even this small $\mathrm{T}_{\mathrm{b}}$ depression could provide relevant energetic savings. During the winter day, a reduction of MR from 6 to $10 \%$ is predicted and, as the winter nighttime body temperature depression is greater, energetic savings of about $10-16 \%$ are predicted (Table 3 ). Thus, this $Q_{10}$ approach yields a greater savings. In either case, the potential value to the animals is clear.

\section{Conclusions}

Recent reports have begun to demonstrate the lability of thermoregulation in mammals [14] and birds [20,33]. Beyond the well-known phenomena of hibernation or daily torpor, these data as well as our observations demonstrate that homeothermy is more dynamic than previously considered. Early observations of torpor suggested that it is used primarily in response to food limitation (e.g., $[16,19])$. Much of that work was done in a laboratory setting and Geiser et al. have shown that patterns of heterothermy in free-living animals differ from those in captivity [12]. However, recent reports on free-living birds support the relationship between torpor and food availability. For example, moon phase, and presumably foraging efficiency, was a stronger predictor of torpor than ambient temperature in Freckled Nightjars [32] and prey availability similarly predicted the use of heterothermy in free-living Owlet-Nightjars [9]. In contrast, others argue that while food availability may contribute, it is not the sole determinant of heterothermy [28]. Carpenter and Hixon [2] showed that $T_{\mathrm{b}}$ reduction is used by migrating hummingbirds to reduce fat loss, even when stores are very high. Our data support Chaplin's [4] argument that regulated $T_{\mathrm{b}}$ reduction may act as the initial response to cold and/or food shortage. Our cardinals had body fat stores ranging from 0.95 to 6.78 grams in the winter, yet all demonstrated a very similar body temperature depression.

Our results support recent research that the use, timing, and depth of heterothermy as a means to conserve energy may be a flexible individual choice that is influenced by several environmental cues (e.g., nutritional status, photoperiod, $T_{\mathrm{a}}$, weather conditions, etc.). Utilizing mild heterothermy has potential advantages. The costs associated with torpor are likely reduced, while energy savings throughout the course of the day may be comparable to those seen with a greater reduction of nighttime $T_{\mathrm{b}}$ (e.g., [7]). Our analysis indicates that even these subtle changes in the normal patterns of thermoregulation during winter cold can produce physiologically significant energy savings. Although torpor is seen across much of the avian phylogeny, it may be that many species are unable to undergo significant reductions in $T_{\mathrm{b}}$. It is tempting to speculate that the ability to undergo mild heterothermy is the basal condition of birds, and may be used widely in species that do not become torpid. The mechanisms driving these alterations, as well as

Table 3 Predicted field metabolic rates (FMR) calculated using previously published cardinal FMR values and our measures of cardinal body temperatures during summer and winter

\begin{tabular}{|c|c|c|c|}
\hline \multirow[t]{2}{*}{$\left(\mathrm{LO}_{2} / \mathrm{h}\right)$} & Measured FMR during winter night ${ }^{a}$ & $\begin{array}{l}\text { Predicted FMR during winter night with summer } \\
\text { night } T_{b}\left(Q_{10}=2\right)\end{array}$ & $\begin{array}{l}\text { Predicted FMR during winter night with summer } \\
\text { night } T_{b}\left(Q_{10}=3\right)\end{array}$ \\
\hline & 0.201 & $0.221(+9.9 \%)$ & $0.233(+16.1 \%)$ \\
\hline \multirow[t]{2}{*}{$\left(\mathrm{LO}_{2} / \mathrm{h}\right)$} & Measured FMR during winter day ${ }^{a}$ & $\begin{array}{l}\text { Predicted FMR during winter day with summer } \\
\text { day } T_{b}\left(Q_{10}=2\right)\end{array}$ & $\begin{array}{l}\text { Predicted FMR during winter day with summer day } \\
T_{\mathrm{b}}\left(Q_{10}=3\right)\end{array}$ \\
\hline & 0.226 & $0.240(+6.2 \%)$ & $0.249(+10.0 \%)$ \\
\hline
\end{tabular}

Predicted FMRs are accompanied by a percent increase from measured FMR, which represents potential energy savings due to winter body temperature depression. Predicted FMRs were calculated using $Q_{10}$ values of both 2 and 3 (exact value is unknown for this species)

a from Sgueoet al. [31] 
the contribution of the resulting energy savings to winter survival should be further assessed.

\section{Availability of supporting data}

The data set supporting the results of this article is available in the DSpace repository at http://hdl.handle. net/2374.MIA/5168.

\section{Authors' contributions}

PJS conceived and designed the experiments. MCK, KRC and PJS participated in the collection of the data. MCK and PJS analyzed the data and PJS performed statistical analysis. MCK wrote the first draft of the manuscript. PJS and $K R C$ revised and wrote the final version of the manuscript. All authors read and approved the final manuscript.

\section{Acknowledgements}

We thank the staff at the Miami University Ecology Research Center for assistance. Funding was provided by the Department of Biology at Miami University, by the National Science Foundation (grant \# 1257455 to PJS) and by a Miami University undergraduate research award to MK. We also thank Michael Hughes from the Miami University Statistical Consulting Center and Dr. Hank Stevens for assistance with the statistical analysis and the extremely insightful comments of our reviewers.

\section{Compliance with ethical guidelines}

\section{Competing interests}

The authors declare that they have no competing interests.

Received: 13 January 2015 Accepted: 11 September 2015

Published online: 01 October 2015

\section{References}

1. Brusilovskiy E (2004) The Piecewise Regression Model as a Response Modeling Tool, NESUG 2004 Conference Proceedings.

2. Carpenter FL, Hixon MA. A new function for torpor: fat conservation in a wild migrant hummingbird. Condor. 1988;90:373-8.

3. Carr JM, Lima L. Nocturnal hypothermia impairs flight ability in birds: a cost of being cool. Proc R Soc B. 2013;280:20131846.

4. Chaplin SB. The physiology of hypothermia in the Black-Capped Chickadee, Parus atricapillus. J Comp Physiol. 1976;112:336-44.

5. Commission for Thermal Physiology of the International Union of Physiological Sciences (IUPS Thermal Commission). Glossary of terms for thermal physiology. Jpn J Physiol. 2001;51:245-80.

6. Cooper SJ, Swanson DL. Seasonal acclimatization of thermoregulation in the Black-capped Chickadee. Condor. 1994;96:638-46.

7. Cooper SJ, Gessaman JA. Nocturnal hypothermia in seasonally acclimatized Mountain Chickadees and Juniper Titmice. Condor. 2005;107:151-5.

8. Dawson WR, Marsh RL, Buttemer WA, Carey C. Seasonal and geographic variation of cold resistance in House Finches Carpodacus mexicanus. Physiol Zool. 1983;56:353-69.

9. Doucette LI, Brigham RM, Pavey CR, Geiser F. Prey availability affects daily torpor by free-ranging Australian owlet-nightjars (Aegotheles cristatus). Oecologia. 2012;169:361-72.

10. Downs CT, Brown M. Nocturnal heterothermy and torpor in the Malachite Sunbird (Nectarinia famosa). Auk. 2002;119:251-60.
11. Dzal YA, Brigham RM. The tradeoff between torpor use and reproduction in little brown bats (Myotis lucifugus). J Comp Physiol B. 2013:183:279-88.

12. Geiser F, Holloway JC, Körtner G, Maddocks TA, Turbill C, Brigham RM. Do patterns of torpor differ between free-ranging and captive mammals and birds? In: Heldmaier G, Klingenspor M, editors. Life in the cold: 11 th international hibernation symposium. Berlin: Springer Verlag; 2000. p. 95-102.

13. Geiser F, Currie SE, O'Shea KA, Hiebert SM. Torpor and hypothermia: reversed hysteresis of metabolic rate and body temperature. Am J Physiol Regul Integr Comp Physiol. 2014;307:R1324-9.

14. Glanville EJ, Seebacher F. Plasticity in body temperature and metabolic capacity sustains winter activity in a small endotherm (Rattus fuscipes). Comp Biochem Physiol A. 2010;155:383-91.

15. Grubb TC Jr, Pravosudov WV. Toward a general theory of energy management in wintering birds. J Avian Biol. 1995;26:255-60.

16. Hainsworth FR, Collins BG, Wolf LL. The function of torpor in hummingbirds. Physiol Zool. 1977;50:215-22.

17. Heldmaier G, RufT. Body temperature and metabolic rate during natural hypothermia in endotherms. J Comp Physiol B. 1992;162:696-706.

18. King JR. Adaptive periodic fat storage in birds. In: KH Voous (ed) Proceedings of the XV Ornithological Congress. E.J. Brill, Leidin, The Netherlands; 1972;200-17.

19. Laurila M, Hohtola E. The effect of ambient temperature and simulated predation risk on fasting-induced nocturnal hypothermia of pigeons in outdoor conditions. J Therm Biol. 2005:30:392-9.

20. Lewden A, Petit M, Milbergue M, Orio S, Vezina F. Evidence of facultative daytime hypothermia in a small passerine wintering at northern latitudes. IBIS. 2014;156:321-39.

21. Maddocks TA, Geiser F. Seasonal variations in thermal energetics of Australian silvereyes (Zosterops lateralis). J Zool. 2000:252:327-33.

22. McKechnie $A E$, Lovegrove $B G$. Avian facultative hypothermic responses: a review. Condor. 2002;104:705-24.

23. Pravosudov W, Lucas JR. The costs of being cool: a dynamic model of nocturnal hypothermia by small food-caching birds in winter. J Avian Biol. 2000;31:463-72

24. Prinzinger R, Preßmar A, Schleucher E. Body temperature in birds. Comp Biochem Physiol. 1991;99A:499-506.

25. Reinertsen RE. Physiological and ecological aspects of hypothermia. In: Carey C, editor. Avian energetics and nutritional ecology. New York: Chapman \& Hall; 1996. p. 125-57.

26. R Core Team: R. A language and environment for statistical computing R Foundation for Statistical Computing, Vienna, Austria. 2014. http:// www.R-project.org/.

27. Schaeffer PJ, Komer KC, Corder KR (2014): Heterothermy in Northern Cardinals. DSpace Database. http://hdl.handle.net/2374.MIA/5168.

28. Schleucher E. Torpor in birds: taxonomy, energetics, and ecology. Physio Biochem Zool. 2004;77:942-9.

29. Schmidt-Nielsen K. Desert animals: physiological problems of heat and water. Oxford: Oxford University Press; 1964.

30. Scholander PF, Hock R, Walters V, Johnson F, Irving L. Heat regulation in some arctic and tropical mammals and birds. Biol Bull. 1950;99:237-58.

31. Squeo C, Wells ME, Russell DR, Schaeffer PJ. Acclimatization of seasonal energetics in Northern Cardinals (Cardinalis cardinalis) through plasticity of metabolic rates and ceilings. J Exp Biol. 2012;215:2418-24.

32. Smit B, Boyles JG, Brigham RM, McKechnie AE. Torpor in dark times: patterns of heterothermy are associated with the lunar cycle in a nocturnal bird. J Biol Rhythms. 2011;26:241-8.

33. Smit B, Harding CT, Hockey PAR, McKechnie AE. Adaptive thermoregulation during summer in two populations of an arid-zone passerine. Ecology. 2013;94:1142-54

34. Swanson DL. Seasonal adjustments in metabolism and insulation in the Dark-eyed Junco. Condor. 1991;93:538-45. 